\title{
Can high levels of renewable energy be cost effective using battery storage? Cost of renewable energy scenarios for an isolated electric grid in Western Australia
}

\author{
Dean Laslett ${ }^{*}$ \\ School of Engineering and Information Technology, Murdoch University, South Street, Murdoch, WA 6150, Australia
}

Received: 23 June 2018 / Accepted: 13 February 2020

\begin{abstract}
Many simulations of very high or 100\% renewable energy electricity systems rely on existing or expanded capacity of utility scale power technologies with long construction lead times, such as hydro power or pumped hydro power. However, globally, the shorter lead time and more distributed technologies of wind power, solar PV, and batteries are expanding rapidly, and costs are falling. Can a grid get to high levels of renewable energy with these technologies alone, along with energy efficiency improvements, at reasonable cost? To address this question, scenarios of partial $(<100 \%)$ renewable electricity supply were simulated for the South-West Interconnected System (SWIS) in the southwest of Western Australia. The SWIS is isolated from other grids, so power balance between supply and demand must be maintained completely within the grid, and there is no significant hydropower capacity to fall back on. Even with no improvement in cost and no carbon price, the partial renewable energy scenarios were found to be less expensive than a fossil fuel "business as usual" scenario up to about $70 \%$ renewable generation. With carbon prices of $\$ 24 /$ tonne and $\$ 70 /$ tonne, the same scenarios were less expensive up to around $80 \%$ and $96 \%$ renewable generation respectively. Hence at current costs, using solar $\mathrm{PV}$, wind, energy efficiency and battery storage technologies are cost effective up to very high levels of renewable energy, but not $100 \%$. However the cost of these technologies are falling rapidly. A simple way to include these continuous cost improvements into the levelised cost of energy calculation was developed, and it was found that if the costs of solar, wind and battery technologies continue to improve at current global rates, then the break even level with conventional generation increases significantly, up to $99 \%$ or above with a carbon price of $\$ 70 /$ tonne and current Australian installed capacity growth rates. Hence a battery based system operating at almost $100 \%$ renewable energy which is no more expensive than a conventional fossil system is foreseeable for the SWIS grid, and perhaps other grids as well.
\end{abstract}

\section{Introduction}

Electricity systems with high levels of variable renewable energy generation are now widely considered able to operate effectively and reliably, although doubts remain [1]. Here renewable energy (or RE) is also taken to include energy efficiency measures and some form of storage. However, there is still a degree of uncertainty about the costs of such electricity systems, compared to the cost of using conventional fossil fuel or nuclear generation. On the one hand, many studies found the cost of RE systems favourable. For example, Mathiesen et al. [2] found that 100 percent RE systems for the country of Denmark may be economically beneficial compared to fossil fuel systems,

\footnotetext{
* e-mail: gaiaquark@gmail.com
}

particularly if externalities such as health costs are counted. Elliston et al. [3] found that the cost of a 100\% renewable energy system for the national grid in Eastern Australia was competitive with fossil fuel based low carbon alternative systems. In the South West of Western Australia, Lu et al. [4] modelled costs for a $100 \% \mathrm{RE}$ scenario using pumped hydro, and found that if 2030 capital prices are used, then the cost is similar to a conventional fossil generation scenario if there is a price on carbon of $\$ 25$ per tonne. Sadiqa et al. [5] found a $100 \%$ renewable system for Pakistan using RE gas storage was less costly than a conventional fossil fuel system. Aghahosseini et al. [6] found that a renewable powered grid spanning the Americas would be less costly than conventional generation. Jacobson et al. [7] modelled a world wide $100 \%$ RE system containing 139 countries and found the overall cost to be less expensive than using 
conventional generation. A more recent similar study found the $100 \%$ RE system to have similar direct costs to the business as usual case [8]. If climate and health costs were included, the RE system was much cheaper.

In contrast, Zappa et al. [9] modelled seven renewable energy scenarios for Europe, and found them to be more expensive than the current system unless nuclear power or carbon capture and storage were used. Connolly et al. [10] modelled an RE system for Europe, including electricity, heat and transport, and found the cost of the system would be more expensive. Riesz et al. [11] found that the lowest cost renewable energy system scenarios for Australia had very high levels of wind power generation, but would be more expensive than the current conventional system. Rose et al. [12] found that an $85 \%$ renewable scenario for the South West of Western Australia would have a matching cost, but a 100\% RE system would be more costly. Cochran et al. [13] conducted a meta study of large scale RE electricity system scenarios around the world, finding that some complete $(100 \%)$ renewable energy scenarios were estimated to be more expensive than an equivalent conventional fossil fuel system, some on a par, and some less costly. A very recent meta study [14] found $100 \% \mathrm{RE}$ scenarios to be the same or more expensive than an equivalent conventional system, unless externalities were included.

However, the costs of wind power and solar PV have fallen rapidly over the past decade, and are continuing to fall, to the point where new build wind power in particular could compete on a purely investment cost basis with new build fossil fuel power stations [15]. Benson and Magee [16] reported a cost improvement rate of around 3\% per year for wind power, and around 9\% per year for solar PV. More recent reports suggest these cost improvement rates are continuing $[17,18]$. Globally, installed capacity of wind and solar PV have also grown rapidly, by about $29 \%$ and $22 \%$ per year respectively [15]. There are some doubts over whether these growth rates can be maintained [19], although in Australia Baldwin et al. [20] forecast they will be exceeded in 2019 .

Many of the most widely available sources of RE, such as wind and solar PV, are variable, and dependent on meteorological conditions. They cannot always generate according to the current level of demand, although there is often a correlation between availability and demand, for example extra air conditioning load on a hot sunny afternoon with high levels of solar radiation. There is also complementarity between different types of RE, such that the generation level of one type can be high when another is low. Hence using more than one type of RE, and also increasing the geographic spread of RE power plants, are options to more fully cover the demand if the availability of one $\mathrm{RE}$ source is low in one region. However this may mean there will be significant excess in generation availability when demand is low. Denholm et al. [21] investigated the effects of increasing levels of RE on an isolated electric grid, and found that costs would become prohibitive because of increasing levels of curtailment of the RE generators when demand was less than the available supply. Adding a form of energy storage decreased curtailment, although there were diminishing returns as the amount of storage increased. This is consistent with the findings of Elliston et al. [22] for the national grid in Eastern Australia. The cost incremented in a mostly linear fashion as the proportion of $\mathrm{RE}$ generation increased, with some cost acceleration above linear increase as the proportion of $\mathrm{RE}$ exceeded $80 \%$.

Hence most very high or $100 \%$ RE studies utilise storage, or a source of energy that can be generated flexibly according to demand, and can compensate for low availability of the variable sources of RE [14]. These include hydroelectricity, pumped hydroelectricity, bio energy, renewable hydrogen or methane conversion, geothermal energy and solar thermal generation and storage. The flexible generation technologies in effect utilise a form of stored energy. Demand side management, which is the controlled withdrawal of non-essential loads, can also be used when demand exceeds supply. Energy efficiency measures have the potential to reduce demand over all time scales.

A common feature of most high RE studies is the reliance on existing or expansion of hydro or pumped hydro capacity as one of the sources of flexible generation to achieve cost competitive 100\% RE systems. All of the studies chosen by Deason [14] for in-depth analysis had this characteristic. Nine out of twelve of the studies assessed by Cochran et al. [13] also used hydro or pumped hydro. One of the exceptional studies, Kemp and Wexler [23], modelled Britain and relied on bio energy, tidal and wave power rather than significant levels of hydro power. The second exception, Lund and Mathieson [24], used biomass and hydrogen electrolysis for flexible generation. The third exception, Connolly et al. [25], relied heavily on bio energy. Another study, Pleßmann et al. [26], also simulated global $100 \%$ RE electricity relying on solar thermal and renewable power to gas storage rather than hydroelectricity.

Use of hydroelectricity or biomass on a large scale may not be feasible in many areas of the world due to topographical or environmental constraints. Even if feasible, these technologies could involve significant installation lead times. The average lead time for hydroelectric projects around the world has been about 8.6 years [27]. There can also be other barriers. For example, even though extensive pumped hydro capacity in the European Union is already available, Kougias and Szabó [28] found that rising levels of RE did not automatically lead to a rise in utilisation rates, and that this might inhibit the needed investment in new capacity. The authors suggested the use of proactive technological, policy and market measures to encourage utilisation and new investment.

However, in the absence of specific policies and planning to enable these large scale and long lead time projects, the use of another storage technology, batteries, is likely to grow. Usually considered for short term storage, battery systems are distributed, scalable from home or car size to utility scale, have short installation times, non dependence on suitable topography or geology, a growing installed base and a cost reduction trajectory. Benson and Magee [16] reported a cost improvement rate of around 3\% per year. However, Nykvist and Benson [29] concluded that EV battery costs had improved at a faster rate of around 
Table 1. Current installed capacity for the SWIS electrical grid (BAU) and renewable energy capacity for each partial renewable scenario $(<100 \% \mathrm{RE})$ by technology type.

\begin{tabular}{llllll}
\hline Scenario & $\begin{array}{l}\text { RE } \\
\text { generation (\%) }\end{array}$ & $\begin{array}{l}\text { Energy efficiency } \\
\text { improvement }\end{array}$ & Solar PV & Wind & $\begin{array}{l}\text { Distributed } \\
\text { storage }\end{array}$ \\
\hline BAU & 17 & $5 \%$ & $1000 \mathrm{MW}$ & $465 \mathrm{MW}$ & - \\
1 & 42 & $25 \%$ & $1000 \mathrm{MW}$ & $1033 \mathrm{MW}$ & $1000 \mathrm{MWh}$ \\
2 & 47 & $30 \%$ & $1000 \mathrm{MW}$ & $1033 \mathrm{MW}$ & $1140 \mathrm{MWh}$ \\
3 & 52 & $30 \%$ & $1710 \mathrm{MW}$ & $1033 \mathrm{MW}$ & $1140 \mathrm{MWh}$ \\
4 & 56 & $30 \%$ & $1710 \mathrm{MW}$ & $1433 \mathrm{MW}$ & $1140 \mathrm{MWh}$ \\
5 & 69 & $30 \%$ & $3420 \mathrm{MW}$ & $1947 \mathrm{MW}$ & $4560 \mathrm{MWh}$ \\
6 & 72 & $30 \%$ & $4000 \mathrm{MW}$ & $1947 \mathrm{MW}$ & $7000 \mathrm{MWh}$ \\
7 & 75 & $30 \%$ & $3420 \mathrm{MW}$ & $2447 \mathrm{MW}$ & $10500 \mathrm{MWh}$ \\
8 & 79 & $30 \%$ & $4500 \mathrm{MW}$ & $2447 \mathrm{MW}$ & $10500 \mathrm{MWh}$ \\
9 & 84 & $30 \%$ & $6840 \mathrm{MW}$ & $2747 \mathrm{MW}$ & $10500 \mathrm{MWh}$ \\
10 & 90 & $30 \%$ & $6840 \mathrm{MW}$ & $3247 \mathrm{MW}$ & $16500 \mathrm{MWh}$ \\
11 & 94 & $30 \%$ & $6840 \mathrm{MW}$ & $3447 \mathrm{MW}$ & $22800 \mathrm{MWh}$ \\
12 & 96 & $30 \%$ & $6840 \mathrm{MW}$ & $4447 \mathrm{MW}$ & $22800 \mathrm{MWh}$ \\
13 & 97 & $30 \%$ & $9000 \mathrm{MW}$ & $4447 \mathrm{MW}$ & $22800 \mathrm{MWh}$ \\
14 & 98 & $30 \%$ & $9000 \mathrm{MW}$ & $4447 \mathrm{MW}$ & $25650 \mathrm{MWh}$ \\
15 & 98.7 & $30 \%$ & $9000 \mathrm{MW}$ & $4447 \mathrm{MW}$ & $33250 \mathrm{MWh}$ \\
16 & 99.5 & $30 \%$ & $14000 \mathrm{MW}$ & $4447 \mathrm{MW}$ & $33250 \mathrm{MWh}$ \\
17 & 99.9 & $30 \%$ & $18000 \mathrm{MW}$ & $4447 \mathrm{MW}$ & $38000 \mathrm{MWh}$ \\
\hline
\end{tabular}

8\%, and Schmidt et al. [30] predicted a faster cost improvement rate of around $7-9 \%$ per year between the years 2015 and 2030. Growth in global installed capacity has been about $33 \%$ per year [31].

Could a very high RE system be cost competitive using batteries alone as the storage system? This study will examine this question by making cost comparisons of different partial renewable energy scenarios using battery storage for the South West Interconnected System (SWIS). The SWIS is an electric grid that supplies the South-West region of Western Australia (SWWA). The present configuration of energy generation systems connected to the SWIS is dominated by conventional fossil fuel power stations. There is also about $460 \mathrm{MW}$ of onshore wind capacity and more than $500 \mathrm{MW}$ of roof top solar PV capacity connected to the SWIS.

Much of the conventional generation capacity is aging [32] and would be due for replacement within the next 15-30 years. Since it is not feasible to replace all the conventional power generation capacity overnight, the SWIS will continue to consist of a combination of conventional and $\mathrm{RE}$ generation, with the percentage of $\mathrm{RE}$ generation most probably increasing in line with the goal of reducing greenhouse emissions. A reason to model the SWIS is that it does not currently have any significant hydro power capacity. Also the SWIS has no connection with any other grid, and so must be entirely self reliant.

The structure of this study is as follows: In the methods section scenarios are developed that push the level of RE used on the SWIS towards $100 \%$, but hydroelectricity, pumped hydro, biomass or solar thermal technology are not used. Instead, differing mixes of wind, solar PV, energy efficiency improvement and distributed battery storage will be simulated, and the cost of energy $(C O E)$ for each scenario is estimated. A business as usual (BAU) scenario is also developed where the load demand of the SWIS grid was met with predominantly conventional fossil fuel generation capacity. The external cost of greenhouse emissions is incorporated into the cost model using a price on equivalent carbon emissions, and a simple method to incorporate cost improvement over the building duration of each scenario into the cost model is introduced. The results and discussion sections find that with no cost improvement of the RE technologies, the partial renewable energy scenarios with no carbon price are less costly than the BAU case for up to around $70 \%$ RE generation (the break even point). If the carbon price is increased or there is cost improvement, then the break even point is pushed higher. With a carbon price, cost improvement and current Australian installation growth rates, the break even point could reach above $99 \% \mathrm{RE}$ generation. This result indicates that it is plausible a 100\% RE grid using only batteries for storage will be cost effective compared to the fossil fuel BAU case. In the final section, the conclusions reached by this study are summarised.

\section{Method}

Seventeen partial renewable energy scenarios for the SWIS grid were considered in this study, each with a different level of renewable technologies used. The installed capacities of each of these technologies are given in Table 1. A business as usual (BAU) scenario was also developed 
whereby the load demand on the SWIS was met using mainly current conventional fossil fuel generation technologies. It was assumed that the cost of the BAU scenario does not change, although it may go up because of increasing fuel costs. The framework to model these scenarios has previously been developed to model $100 \%$ renewable energy (RE) scenarios for the SWIS on an hourby-hour basis [33-35]. Hourly power generation profiles were synthesised for each scenario, based on the installed capacity of each renewable energy technology and statistical profiles of wind speed and solar radiation. These profiles were compared to the hourly load profile over a period of one year to estimate the percentage of $\mathrm{RE}$ generation.

In general terms, for each scenario the cost of energy $(C O E)$ was estimated by aggregating the cost of each power plant and new grid infrastructure within the scenario. The cost of an individual power plant itself has several components, each of which must be calculated (Fig. 1). To incorporate a price on carbon into the cost calculation, the greenhouse emission intensity was first calculated. A capital recovery factor, capital cost improvement factor and inflation ratio factor were also calculated to represent the monetary effects of time. All the cost components were then summed to obtain the cost of each power plant, and finally the cost of all power plants were aggregated and divided by the total energy generated by all plants to establish the $C O E$ of the scenario.

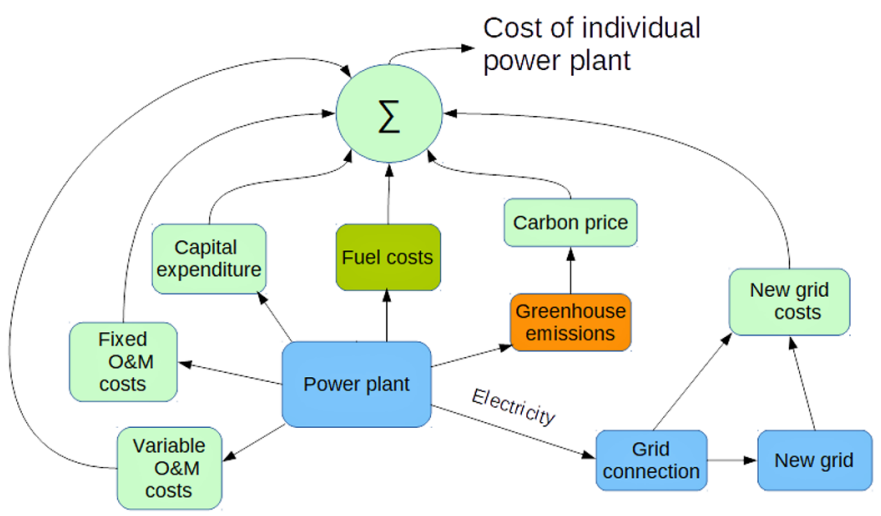

Fig. 1. Components of the cost of an individual power plant. O\&M stands for operations and maintenance.

\subsection{Calculation of emission intensity}

Renewable energy power plants use no fossil fuels, so greenhouse emissions come from embodied emissions of construction and operation of the power plant. In contrast, for fossil fuel plants, the majority of the emissions come from combustion of the fuel [36]. Therefore the emissions from each type of power plant must be treated differently. The individual emissions intensity $E I_{n}\left(\mathrm{kgCO}_{2} \mathrm{e} / \mathrm{MWh}\right)$ for a renewable energy power plant $n$ (one of a fleet of plants in a scenario) was estimated by pro-rating the embodied emissions over the lifetime of the plant:

$$
E I_{n}=\frac{E R E_{n} c a p_{n}}{l f_{n} e_{n}}
$$

where $c a p_{n}$ is the capacity of the plant (MW), $l f_{n}$ is the plant lifetime $(\mathrm{y}), E R E_{n}$ is the specific emission intensity per unit of capacity $\left(\mathrm{kgCO}_{2} \mathrm{e} / \mathrm{MW}\right)$, and $e_{n}$ is the annual energy generated (MWh). The emissions of storage were calculated by defining $E R E_{n}$ in terms of MWh of battery capacity instead of MW. The emissions from energy efficiency measures are uncertain but were set at zero, although some EE measures might have emissions from the embodied emissions of building materials. For fossil fuel plants, the individual emissions intensity was estimated using:

$$
E I_{n}=E F_{n}
$$

where $E F_{n}$ is the specific emission intensity per unit of energy generated $\left(\mathrm{kgCO}_{2} \mathrm{e} / \mathrm{MWh}\right)$. The values for $E R E_{n}$, $E F_{n}$ and $l f_{n}$ used in this study are given in Tables 2 and 3.

The emissions from building new transmission lines to connect a power station was estimated using:

$$
E T_{n}=\frac{T L F \text { tlength }}{n+T C F}
$$

where $T L F$ is the transmission line specific emissions intensity $\left(\mathrm{kgCO}_{2} \mathrm{e} / \mathrm{km}\right), T C F$ is the converter specific emissions intensity $\left(\mathrm{kgCO}_{2} \mathrm{e}\right)$, tlength ${ }_{n}$ is the length of new transmission line required $(\mathrm{km}), l f_{t l}$ is the lifetime of transmission lines (y), and $E T_{n}$ is the total emissions from building new transmission lines to connect plant $n$ to the grid $\left(\mathrm{kgCO}_{2} \mathrm{e}\right)$. Transmission line greenhouse emissions were pro-rated over the lifetime of the lines. The values of transmission line emission parameters are given in Table 4.

Table 2. Specific emission intensities and plant lifetimes for different energy generation and storage technologies.

\begin{tabular}{lll}
\hline Technology & Specific emissions $E I$ & Reference \\
\hline Roof top solar PV & $1.8424 \times 10^{6} \mathrm{~kg} / \mathrm{MW}$ & Good et al. [37] \\
Utility scale solar PV & $1.8424 \times 10^{6} \mathrm{~kg} / \mathrm{MW}$ & Good et al. [37] \\
Wind & $1.2749 \times 10^{6} \mathrm{~kg} / \mathrm{MW}$ & Kumar et al. [38] \\
Storage & $75000 \mathrm{kgCO}_{2} \mathrm{e} / \mathrm{MWh}$ capacity & Larcher and Tarascon [39] \\
Coal & $950 \mathrm{kgCO}_{2} \mathrm{e} / \mathrm{MWh}$ & Kelp and Dundas [40] \\
Gas & $600 \mathrm{kgCO}_{2} \mathrm{e} / \mathrm{MWh}$ & Kelp and Dundas [40] \\
\hline
\end{tabular}


Table 3. Plant lifetimes for different energy generation and storage technologies.

\begin{tabular}{lll}
\hline Technology & $\begin{array}{l}\text { Lifetime } \\
l f \text { (years) }\end{array}$ & Reference \\
\hline Roof top solar PV & 30 & Good et al. [37] \\
Utility scale solar PV & 30 & Good et al. [37] \\
Wind & 25 & Kumar et al. [38] \\
Storage & 15 & Nicholls et al. [41] \\
Energy efficiency & 15 & Hoffman et al. [42] \\
Coal & 30 & EPRI [43] \\
Gas & 30 & EPRI [43] \\
\hline
\end{tabular}

Table 4. Transmission line emission parameters.

\begin{tabular}{lll}
\hline Parameter & Value & Reference \\
\hline$T L F$ & $7000 \mathrm{kgCO}_{2} \mathrm{e} / \mathrm{km}$ & Turconi et al. [44] \\
$T C F$ & $100,000 \mathrm{kgCO}_{2} \mathrm{e}$ & Turconi et al. [44] \\
$l f_{t l}$ & 40 years & Hauan [45] \\
\hline
\end{tabular}

The overall emissions intensity for each scenario, $E I$, in $\mathrm{kgCO}_{2} \mathrm{e} / \mathrm{MWh}$, was calculated using:

$$
E I=\frac{\sum_{n=1}^{N P R E} \frac{E R E_{n} c a p_{n}}{l f_{n}}+\sum_{n=1}^{N P F} E F_{n} e_{n}+\sum_{n=1}^{N P} E T_{n}}{\sum_{n=1}^{N P} e_{n}}
$$

where NPRE is the number of renewable energy power plants, $N P F$ is the number of fossil plants, and $N P$ is the number of power plants in the scenario $(N P=N P R E+$ $N P F)$.

\subsection{Calculation of the cost of each power plant}

To represent the monetary effects of time, the cost for each individual power plant was estimated in a similar fashion to the simple levelised cost of energy calculator at NREL [46]. A capital recovery factor $\left(C R F_{n}\right)$ was calculated, so that the annual required capital investment could be quantified:

$$
C R F_{n}=\frac{d(1+d)^{l f_{n}}}{(1+d)^{l f_{n}}-1} C I F_{n}
$$

where $d$ is the fractional discount rate (often set to the cost of finance or interest rate to reflect the opportunity cost of financing the power plant rather than earning interest), and $l f_{n}$ is the plant lifetime (y). Since the cost of RE technologies are currently decreasing at a significant rate each year, an approach was developed to incorporate this change into the estimation of COE over the duration of building the entire RE system. Therefore a capital cost

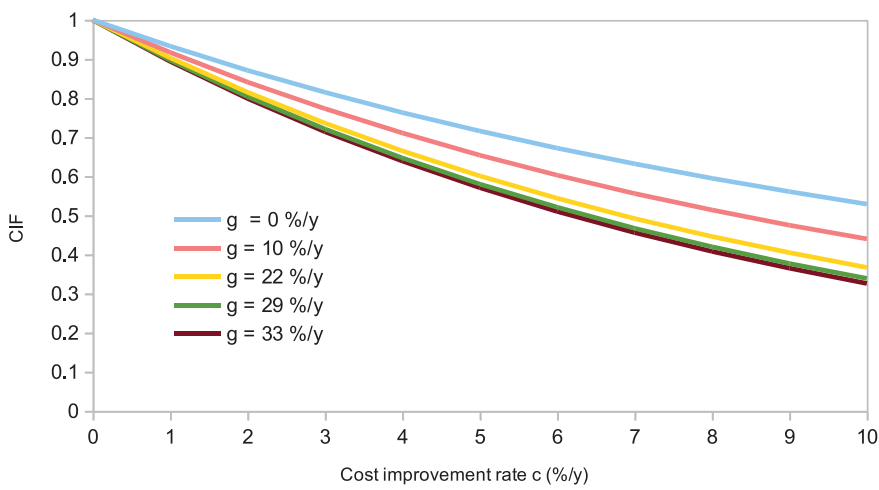

Fig. 2. Capital cost improvement factor (CIF) versus cost improvement rate for different installation growth rates $(\mathrm{g})$. The effect of cost improvement on the overall capital cost of a wind, solar PV or battery system increases with higher installation growth rates.

improvement factor for each power plant $n\left(C I F_{n}\right)$ was introduced, and calculated based on yearly cost improvement and installation growth rate over a set duration:

$$
C I F_{n}=\frac{\sum_{i=0}^{t_{b d}-1}\left(1-c_{n}\right)^{i}\left(1+g_{n}\right)^{i}}{\sum_{i=0}^{t_{b d}-1}\left(1+g_{n}\right)^{i}}
$$

where $c_{n}$ is the yearly fractional cost improvement for plant $n$, and $g_{n}$ the yearly fractional increase in installation rate for plant $n$, and $t_{b d}$ the system building duration (y). A higher $g_{n}$ magnifies the effect of cost improvement (Fig. 2). If there is no cost improvement, $C I F_{n}$ is set to a value of 1 .

An inflation ratio factor $\left(I R F_{n}\right)$ was also calculated so that inflation could be accounted for:

$$
I R F_{n}=\frac{(1+i)^{l f_{n}}-1}{i l f_{n}}
$$

where $i$ is the fractional inflation rate. It can be expected that some portion of the plant capacity is off line at any one time for troubleshooting or routine maintenance. This was assumed to be a constant percentage of the total capacity. The online fraction $o l f_{n}$ was defined as:

$$
o l f_{n}=1-\frac{\text { capcdown }_{n}}{100}
$$

where capcdown $_{n}$ is the average percentage of the capacity that is off line at any one time. The total capital cost of a power plant was then calculated as:

$$
\operatorname{capcost}_{n}=\frac{C C_{n} c a p_{n}}{o l f_{n}}
$$

where for plant $n$, capcost $_{n}$ is the capital cost of the plant, and $C C_{n}$ is the capital cost factor (cost/MW). The capital cost of storage was calculated by defining $c a p_{n}$ and $C C_{n}$ in 
terms of MWh of battery capacity instead of MW. Although these formulae can be applied to any currency, in this study any dollar value given is Australian dollars.

The capital cost of new transmission line and connection infrastructure for utility scale power plants was estimated using:

$$
\text { gridcost }_{n}=\text { TLC tlength } h_{n}+C C C
$$

Table 5. New grid costs.

\begin{tabular}{lll}
\hline Parameter & Value & Reference \\
\hline$T L C$ & $\$ 1$ million & Krieg [47] \\
& per km & \\
$C C C$ & $\$ 105,340$ & ERA [48] \\
$G C C$ for rooftop PV & $\$ 170$ per kW & CEC [49] \\
$G C C$ for distributed & $\$ 25$ per kWh & CEC [49] \\
storage & & \\
\hline
\end{tabular}

All costs are in Australian dollars.

Table 6. Down time for different energy generation or storage technologies.

\begin{tabular}{lll}
\hline Technology & $\begin{array}{l}\text { Down time } \\
\text { capcdown (\%) }\end{array}$ & Reference \\
\hline Roof top solar PV & 1.5 & Jacobson et al. [50] \\
Utility scale solar PV & 1.5 & Jacobson et al. [50] \\
Wind & 3 & Faulstich et al. [51] \\
Storage & 10 & Dubarry et. al. [52] \\
Energy efficiency & $0^{*}$ & \\
Coal & 16.83 & Cochran et al. [53] \\
Gas & 15 & Gouveia et al. [54] \\
* Energy efficiency measures chosen to involve intrinsic or passive \\
design improvements with no down time, or active systems with \\
equivalent or better reliability than those they replace.
\end{tabular}

where $T L C$ is the capital cost factor for new transmission lines (cost $/ \mathrm{km}), C C C$ is the capital cost factor for new converter equipment, and gridcost $t_{n}$ is the capital cost of the required new grid infrastructure for plant $n$. For distributed rooftop PV and storage, the grid connection cost was estimated using:

$$
\operatorname{gridcost}_{n}=10^{3} G C C \times \mathrm{cap}_{n}
$$

where $G C C$ is the grid connection cost factor (cost $/ \mathrm{kW}$ capacity for rooftop $\mathrm{PV}$ and cost/kWh capacity for storage). The values used for these parameters are given in Table 5.

The annual cost of each individual power plant $\left(\right.$ cost $\left._{n}\right)$ could then be estimated:

$$
\begin{aligned}
\operatorname{cost}_{n}= & C R F_{n}\left(\text { capcost }_{n}+\text { gridcost }_{n}\right)+I R F_{n}\left(O M C_{f n} c a p_{n}\right. \\
& \left.+e_{n}\left(O M C_{v n}+F C_{n}+10^{-3} C P E I_{n}\right)\right)
\end{aligned}
$$

where $C P$ is the carbon price (cost/tonne $\left.\mathrm{CO}_{2} \mathrm{e}\right), O M C_{f n}$ is the annual fixed operation and maintenance cost (cost/ $\mathrm{MW}), O M C_{v n}$ is the annual variable operation and maintenance cost (cost/MWh), $F C_{n}$ is the fuel cost (cost/MWh), and $E I_{n}$ is the emissions intensity for the technology $\left(\mathrm{kgCO}_{2} \mathrm{e} / \mathrm{MWh}\right)$. The fuel cost only applies to fossil fuel plants. The annual fixed operation and maintenance cost of storage was calculated by defining $O M C_{f n}$ in terms of MWh of battery capacity instead of MW. The values for capcdown $, C C_{n}, O M C_{f n}, O M C_{v n}$ and $F C_{n}$ for each technology are given in Tables 6 to 10. Energy efficiency measures were assumed to have no down time.

\subsection{Calculation of the cost of energy for each scenario}

The overall $C O E$ for each scenario in terms of cost per unit of energy used (cost/MWh) was estimated by summing the annual cost for each plant and dividing by the sum of the annual energy generated by each power plant:

$$
C O E=\frac{\sum_{n=1}^{N P} \cos t_{n}}{\sum_{n=1}^{\mathrm{NP}} e_{n}}
$$

Table 7. Capital cost factors for different energy generation, storage or efficiency technologies.

\begin{tabular}{lll}
\hline Technology & $\begin{array}{l}\text { Capital cost factor } C C \\
(\$ \text { million/MW) }\end{array}$ & Reference \\
\hline Roof top solar PV & 1.7 & Blakers et al. [55] \\
Utility scale solar PV & 1.7 & Blakers et al. [55] \\
Wind & 2.3 & Blakers et al. [55] \\
Storage & $0.265 \$$ million/MWh & Field [56] \\
Energy efficiency & $\$ 350$ per $(\mathrm{MWh}$ saved per year) & Jacobs [57] \\
Coal & 3 & EPRI [43] \\
Gas & 1.45 & EPRI [43] \\
\hline
\end{tabular}

All costs are in Australian dollars. 
Table 8. Fixed annual operating and maintenance costs for different energy generation or storage technologies.

\begin{tabular}{lll}
\hline Technology & $\begin{array}{l}\text { Fixed annual operating and } \\
\text { maintenance cost } O M C_{f}(\$ / \mathrm{MW})\end{array}$ & Reference \\
\hline Roof top solar PV & 0 & EPRI [43] \\
Utility scale solar PV & 25,000 & EPRI [43] \\
Wind & 35,000 & Blakers et al. [55] \\
Storage & $2000 \$ / \mathrm{MWh}$ & Brinsmead et al. [58] \\
Energy efficiency & $0^{*}$ & \\
Coal & 45,000 & EPRI [43] \\
Gas & 2000 & EPRI [43] \\
\hline
\end{tabular}

* The annual operating and maintenance cost of energy efficiency measures is often zero or even negative (the operating and maintenance cost of the building, appliance or process is reduced). All costs are in Australian dollars.

Table 9. Variable annual operating and maintenance costs for different energy generation and storage technologies.

\begin{tabular}{lll}
\hline Technology & $\begin{array}{l}\text { Variable annual operating and } \\
\text { maintenance cost } O M C_{v}(\$ / \mathrm{MWh})\end{array}$ & Reference \\
\hline Roof top solar PV & 0 & EPRI [43] \\
Utility scale solar PV & 0 & EPRI [43] \\
Wind & 10 & Blakers et al. [55] \\
Storage & 3.1 & Brinsmead et al. [58] \\
Energy efficiency & $0^{*}$ & \\
Coal & 2.5 & EPRI [43] \\
Gas & 1.5 & EPRI [43] \\
\hline
\end{tabular}

${ }^{*}$ The annual operating and maintenance cost of energy efficiency measures is often zero or even negative (the operating and maintenance cost of the building, appliance or process is reduced). All costs are in Australian dollars.

Table 10. Fuel costs for different fossil energy generation technologies.

\begin{tabular}{lll}
\hline Technology & Fuel cost & Reference \\
& $F C(\$ / \mathrm{MWh})$ & \\
\hline Coal & 27 & EPRI [43] \\
Gas & 54.5 & Lu and Hyland [59] \\
\hline
\end{tabular}

All costs are in Australian dollars.

To compare the model used in this study to the findings of Rose et al. [12], a discount rate of $8 \%$ and an inflation rate of $2 \%$ were used to broadly match the discount rates used in that study. Otherwise a discount rate of $5 \%$ and an inflation rate of $2 \%$ were used to reflect currently low interest rate levels in Australia [4].

To explore the effect of variation in the cost parameters, the Sensitivity, $S_{i}$, of the COE to each cost parameter was estimated using:

$$
S_{i}=\frac{\Delta C O E}{C O E} \frac{P_{i}}{\Delta P_{i}}
$$

where $P_{i}$ is any one of the cost parameters in the above tables. $P_{i}$ was varied $\pm 5 \%$ from its nominal value and $\mathrm{COE}$ recalculated, such that $\Delta P_{i}=0.1 P_{i}$ and $\Delta \mathrm{COE}=\mathrm{COE}_{+5 \%}$ - $\mathrm{COE}-5 \%$.

Initially, no cost improvement or growth in installation rate was set $(c=0, g=0)$. The effect on the COE for each scenario of cost improvement and growth in installation rates was investigated by setting the $c$ parameter for solar $\mathrm{PV}$, wind and battery storage to the currently observed global trends, and the $g$ parameter to both a moderate installation growth rate setting and a more rapid growth rate setting, reflecting current Australian trends (Tab. 11). The building duration $t_{b d}$ was set to 15 years to reflect the short construction time frame needed to ramp up RE generation quickly and reduce greenhouse emissions fast enough to limit global temperature rise to $1.5^{\circ} \mathrm{C}$ and forestall dangerous climate change [60].

\section{Results}

In this section the cost of energy ( $C O E$ ) of scenarios with increasing levels of $\mathrm{RE}$ generation are compared to the $C O E$ of the fossil fuel business as usual (BAU) case. In previous studies it was found that the cost of renewable 
Table 11. Cost improvement and installation growth rates for wind, solar PV and battery storage.

\begin{tabular}{llll}
\hline Technology & $\begin{array}{l}\text { Global cost improvement } \\
\text { rate (\% per year) }\end{array}$ & $\begin{array}{l}\text { Moderate installation growth } \\
\text { rate (\% per year) }\end{array}$ & $\begin{array}{l}\text { Rapid installation growth } \\
\text { rate (\% per year) }\end{array}$ \\
\hline Wind & 3 & 10 & 22 \\
Solar PV & 9 & 10 & 29 \\
Batteries & 8 & 10 & 33 \\
\hline
\end{tabular}

Table 12. Estimated emission intensity and provisional energy cost in $\$ / \mathrm{MWh}$ for each partial renewable scenario for the SWIS electrical grid under different carbon pricing schemes (20 runs).

\begin{tabular}{llllll}
\hline Scenario & $\begin{array}{l}\text { \% RE } \\
\text { generation }\end{array}$ & $\begin{array}{l}\text { Emission intensity } \\
\left(\mathrm{kgCO}_{2} \mathrm{e} / \mathrm{MWh}\right)\end{array}$ & $\begin{array}{l}\text { Cost }(\$ / \mathrm{MWh}) \\
\text { no carbon price }\end{array}$ & $\begin{array}{l}\text { Cost }(\$ / \mathrm{MWh}) \\
\$ 24 / \text { tonne }\end{array}$ & $\begin{array}{l}\text { Cost }(\$ / \mathrm{MWh}) \\
\$ 70 / \text { tonne }\end{array}$ \\
\hline BAU & 17 & 667 & 95.7 & 111 & 142 \\
1 & 42 & 444 & 88.4 & 99.2 & 119 \\
2 & 47 & 394 & 84.6 & 94.2 & 112 \\
3 & 52 & 301 & 86.1 & 93.0 & 107 \\
4 & 56 & 273 & 86.2 & 92.7 & 105 \\
5 & 69 & 199 & 93.9 & 98.2 & 108 \\
6 & 72 & 187 & 97.7 & 102 & 111 \\
7 & 75 & 165 & 100 & 104 & 114 \\
8 & 79 & 145 & 104 & 107 & 127 \\
9 & 85 & 124 & 119 & 122 & 132 \\
10 & 90 & 85.7 & 125 & 127 & 137 \\
11 & 94 & 61.4 & 132 & 134 & 157 \\
12 & 96 & 53.4 & 141 & 155 & 159 \\
13 & 97.4 & 50.8 & 153 & 158 & 168 \\
14 & 97.8 & 47.6 & 156 & 165 & 196 \\
15 & 98.8 & 45.3 & 164 & 193 & 223 \\
16 & 99.5 & 51.9 & 192 & 222 & \\
17 & 99.9 & 59.5 & 219 & & \\
\hline
\end{tabular}

$\mathrm{BAU}$ is the business as usual case of using mostly conventional fossil generation. All costs and prices are in Australian dollars.

energy systems was competitive with fossil fuel systems, but rose sharply at very high levels of RE. So it is initially expected that the RE $C O E$ will be lower, but as RE levels rise, there will be a "break even" point where the two COEs are the same. At even higher levels of RE, the $C O E$ will be higher than the BAU case. The effect of carbon price and $\mathrm{RE}$ cost improvement rate on the break even point is explored, and a sensitivity analysis of the parameters used to estimate the $C O E$ for each scenario is also carried out.

Firstly, to confirm the model calibration, the BAU scenario of this study was compared to the BAU scenario presented by Rose et al. [12] for the SWIS grid. The COE of the BAU scenario with a discount rate of $8 \%$ and a carbon price of $\$ 30 /$ tonne was $129 \$ / \mathrm{MWh}$, which matched the $C O E$ for business as usual of $\$ 129 /$ MWh given by Rose et al. [12] with the same carbon price. For this study, the $C O E$ for the BAU case and the partial renewable energy scenarios was estimated with a discount rate of $5 \%$ (to better reflect current financial conditions) and three different carbon prices: none, $\$ 24 /$ tonne and $\$ 70 /$ tonne (Tab. 12). The COE for the BAU case with these carbon prices was estimated to be $\$ 95.7 / \mathrm{MWh}, \$ 111 / \mathrm{MWh}$ and $\$ 142 / \mathrm{MWh}$ respectively.

Figures 3-5 show cost curves of the partial renewable energy scenarios compared to the BAU case as the level of $\mathrm{RE}$ rises. The break-even point occurs where the curves cross the dotted BAU line. The $C O E$ for the scenarios with no carbon price were less than the BAU for up to around $70 \%$ RE generation (Fig. 3 , black line). For a carbon price of $\$ 24 /$ tonne, the $C O E$ for the scenarios was less than BAU for up to around $80 \%$ renewable energy generation (Fig. 4, black line). For a carbon price of $\$ 70$ /tonne, the break even COE occurred around 96\% RE generation (Fig. 5, black line). Hence increasing the carbon price tended to flatten the cost curve, increasing the break-even level of renewable generation (Tab. 14). The lowest COE occurred at around 




Fig. 3. Cost of partial renewable energy generation scenarios compared to business as usual (BAU) case (dashed line) with no carbon price. Renewable technologies used are wind, solar photovoltaic and distributed battery storage. Black line is no cost improvement over time, blue line is global cost improvement rates and moderate installation growth rates. Green line is global cost improvement rates and rapid installation growth rates. Cost is in Australian dollars.

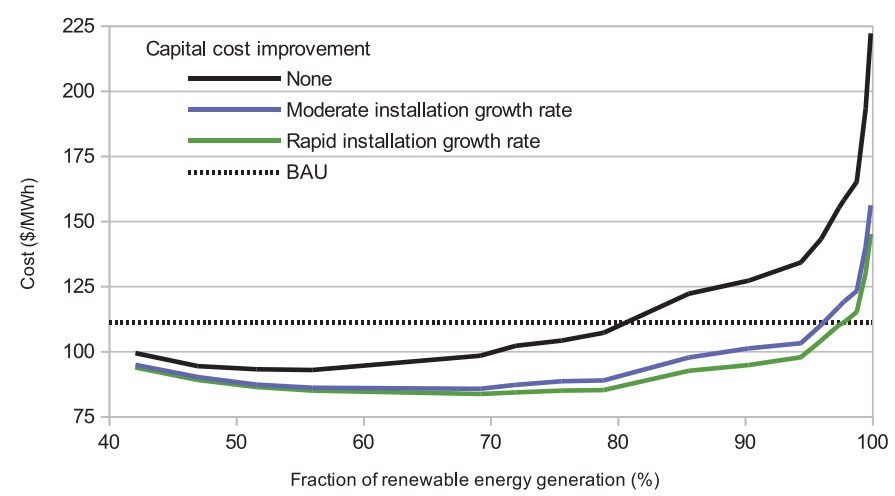

Fig. 4. Cost of partial renewable energy generation scenarios compared to business as usual (BAU) case (dashed line) with a $\$ 24$ per tonne carbon price. Renewable technologies used are wind, solar photovoltaic and distributed battery storage. Black line is no cost improvement over time, blue line is global cost improvement rates and moderate installation growth rates. Green line is global cost improvement rates and rapid installation growth rates. Cost is in Australian dollars.

45-55\% RE generation with no carbon price, and around $50-60 \% \mathrm{RE}$ generation for carbon prices at $\$ 24 /$ tonne and $\$ 70 /$ tonne. For very high levels of renewable energy generation (>95\%), the COE rose sharply, almost in an exponential like manner.

Sensitivity analysis of the parameters used to estimate the $C O E$ for each scenario revealed that the cost was most sensitive to investment parameters (discount rate, inflation rate and carbon price), capital cost parameters, fixed and variable $\mathrm{O}+\mathrm{M}$ costs and plant lifetime. The most sensitive parameter was discount rate (Tab. 13), and the sensitivity to this parameter increased with the level of RE. Therefore, decreasing the discount rate would increase the break-even

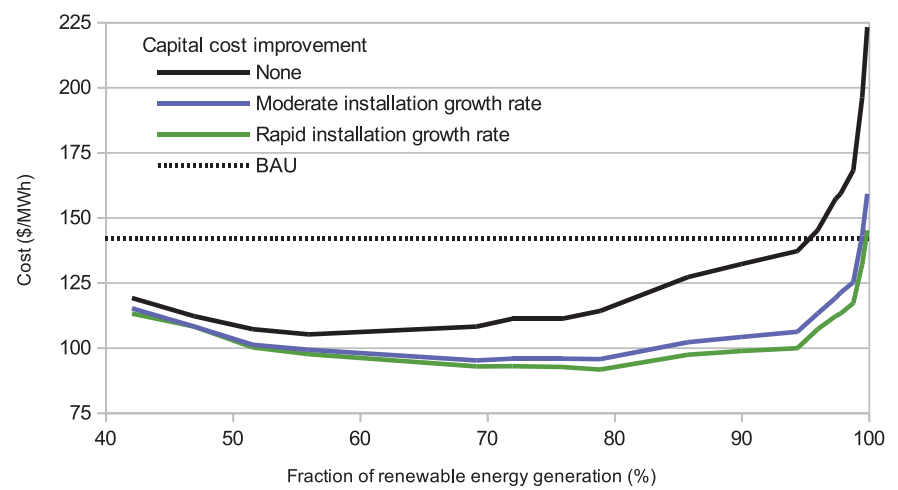

Fig. 5. Cost of partial renewable energy generation scenarios compared to business as usual (BAU) case (dashed line) with a $\$ 70$ per tonne carbon price. Renewable technologies used are wind, solar photovoltaic and distributed battery storage. Black line is no cost improvement over time, blue line is global cost improvement rates and moderate installation growth rates. Green line is global cost improvement rates and rapid installation growth rates. Cost is in Australian dollars.

level of RE and vice versa. In contrast, sensitivity to the inflation rate decreased with increasing $\mathrm{RE}$. These effects could be due to the higher required capital expenditure and absence of fuel costs of the RE technologies. Inclusion of a carbon price generally decreased the sensitivity to other parameters, and not surprisingly, the BAU scenario was most sensitive to the carbon price.

These sensitivity estimates were consistent with improvements in the capital cost of $\mathrm{RE}$ technologies reducing the $C O E$ of the high $\mathrm{RE}$ scenarios the most. If current global improvement rates in wind, solar PV and battery costs were implemented, along with installation growth rates consistent with current Australian trends (Tab. 11), then the break even cost points for the RE scenarios compared to the BAU scenario were increased (Tab. 14 and Figs. 3-5). With no carbon price, the break even point rose to around $95 \% \mathrm{RE}$, and with a carbon price of $\$ 70$ per tonne, the break even point was above $99 \%$. Even with more moderate installation growth rates, the break even point with no carbon price rose to $85 \%$, and with a $\$ 70$ per tonne carbon price was at $99 \%$.

\section{Discussion}

Based on current technology costs, as RE generation increased from low levels, the cost dropped, reaching a minimum around 45-60\% RE generation. The cost then rose again in a roughly linear fashion as RE increased up to about $80 \%$ RE generation, similar to the findings of Elliston et al. [22]. The cost increased more sharply up to around 95\% RE generation, which was also noticed by Elliston et al. [22], and then increased steeply, almost in an exponential like way, at very high levels of $\mathrm{RE}$ generation above $95 \%$. Hence the vanishing returns found by Denholm et al. [21] from adding capacity to cover increasingly 
Table 13. Sensitivity of scenario cost to parameters.

\begin{tabular}{|c|c|c|c|c|c|c|c|}
\hline \multirow[t]{2}{*}{ Parameter class } & \multirow[t]{2}{*}{ Parameter } & \multicolumn{3}{|c|}{ Scenarios No carbon price } & \multicolumn{3}{|c|}{ Scenarios $\$ 70$ per tonne carbon price } \\
\hline & & $\mathrm{BAU}$ & $52 \% \mathrm{RE}$ & $99.9 \% \mathrm{RE}$ & $\mathrm{BAU}$ & $52 \% \mathrm{RE}$ & $99.9 \% \mathrm{RE}$ \\
\hline \multirow{3}{*}{ Investment environment } & Discount rate & 22.4 & 23.3 & 39.0 & 14.8 & 18.6 & 38.3 \\
\hline & Inflation rate & 18.7 & 16.8 & 5.52 & 12.6 & 13.5 & 5.46 \\
\hline & Carbon price & - & - & - & 33.0 & 19.9 & 1.87 \\
\hline \multirow{6}{*}{ Capital cost } & Rooftop solar PV & 4.49 & 8.50 & 35.0 & 3.06 & 6.74 & 33.8 \\
\hline & Wind & 3.08 & 7.58 & 12.8 & 2.10 & 6.01 & 12.3 \\
\hline & Storage & & 1.31 & 17.2 & - & 1.04 & 16.5 \\
\hline & Efficiency & 1.45 & 9.80 & 3.83 & 0.99 & 7.77 & 3.70 \\
\hline & Coal & 12.7 & - & - & 8.64 & - & - \\
\hline & Gas & 17.8 & 16.2 & 4.01 & 11.4 & 13.0 & 4.92 \\
\hline \multirow{5}{*}{$\begin{array}{l}\text { Fixed annual operation } \\
\text { and maintenance costs }\end{array}$} & Rooftop solar PV & 1.37 & 2.60 & 10.7 & 0.94 & 2.06 & 10.3 \\
\hline & Wind & 0.85 & 2.08 & 3.51 & 0.58 & 1.65 & 3.39 \\
\hline & Storage & - & 0.12 & 1.54 & - & 0.09 & 1.49 \\
\hline & Coal & 3.95 & - & - & 2.69 & - & - \\
\hline & Gas & 5.12 & 4.65 & 1.15 & 3.26 & 3.74 & 1.41 \\
\hline \multirow{6}{*}{$\begin{array}{l}\text { Variable operation } \\
\text { and maintenance costs }\end{array}$} & Wind & 0.56 & 1.52 & 2.52 & 0.41 & 1.10 & 2.46 \\
\hline & Storage & - & 0.04 & 0.18 & - & 0.03 & 0.17 \\
\hline & Coal & 1.66 & - & - & 1.13 & - & - \\
\hline & Gas & 0.76 & 1.16 & 0.00 & 0.52 & 0.93 & 0.003 \\
\hline & Coal fuel cost & 17.9 & - & - & 12.2 & - & - \\
\hline & Gas fuel cost & 27.7 & 42.2 & 0.04 & 18.8 & 34.1 & 0.10 \\
\hline \multirow{6}{*}{ Plant lifetime } & Roof-top solar PV & -1.81 & -3.43 & -14.1 & -1.35 & -2.98 & -15.1 \\
\hline & Wind & -1.24 & -3.19 & -5.49 & -0.87 & -2.72 & -5.63 \\
\hline & Storage & - & -0.73 & -9.42 & & -0.59 & -9.41 \\
\hline & Efficiency & -0.86 & -5.80 & -2.27 & -0.59 & -4.60 & -2.21 \\
\hline & Coal & 2.06 & - & - & 1.39 & - & - \\
\hline & Gas & 3.07 & 8.64 & -1.44 & 2.33 & 7.01 & -1.54 \\
\hline
\end{tabular}

Table 14. Carbon price and level of renewable energy generation for break-even cost with BAU with cost improvement and installation growth.

\begin{tabular}{lllll}
\hline $\begin{array}{l}\text { Carbon price } \\
(\$ / \text { tonne) }\end{array}$ & $\begin{array}{l}\text { Cost of BAU } \\
\text { scenario } \\
(\$ / \text { MWh })\end{array}$ & $\begin{array}{l}\text { Break even RE generation } \\
\text { with no cost improvement } \\
\text { or installation rate } \\
\text { growth }(\%)\end{array}$ & $\begin{array}{l}\text { Break even RE generation } \\
\text { with cost improvement } \\
\text { and moderate installation } \\
\text { rate growth }(\%)\end{array}$ & $\begin{array}{l}\text { Break even RE } \\
\text { generation with cost } \\
\text { improvement and } \\
\text { rapid installation } \\
\text { rate growth }(\%)\end{array}$ \\
\hline 0 & 95.7 & 70 & 85 & 95 \\
24 & 111 & 80 & 96 & 98 \\
70 & 142 & 96 & 99 & 99.5 \\
\hline
\end{tabular}

BAU is the business as usual case of using mostly conventional fossil generation. All costs and prices are in Australian dollars.

infrequent meteorological conditions of prolonged low wind speed and solar irradiance were also indicated by this study. Most of the time, generation from this capacity is not needed and hence curtailed.
Therefore a $100 \%$ RE system for the SWIS based on wind, solar PV and battery storage would be more costly than a conventional system based on current technology costs. However, it can clearly be seen that replacing 
conventional fossil generation with renewable energy rather than more conventional plants will be the least cost option up to high levels of RE generation, with a cost break even point of around $70 \%$ even without a price on carbon. Any policy system that results in a price on carbon will make the break even point higher.

Denholm et al. [21] and other studies have suggested that interconnection with another grid, or a form of renewable energy that is capable of being stored for longer time scales, such as biomass, renewable power to gas, or pumped hydro, combined with the use of demand management, might be a more cost effective way to cover the final 5-10\% of RE generation capacity to achieve a low emission $100 \%$ renewable electricity system. However, the cost of wind power has been falling in the last few years, and the cost of solar and battery storage is also currently falling rapidly. The results of this study show that if costs continue to improve on the same trajectory as currently observed, and installation rates grow even at a moderate rate of $10 \%$, then the break even point with BAU will increase significantly, up to $85 \%$ RE with no carbon price. With a carbon price of $\$ 24$ per tonne, the break even point reaches $96 \%$ RE. With a higher carbon price and/or faster cost improvement and installation growth rates, the cost advantage of using a conventional fossil generation system begins to vanish altogether, and a cost effective $100 \%$ RE system based on batteries is foreseeable.

\section{Conclusions}

In this study the cost effectiveness of using high levels of distributed renewable energy, and batteries as the only major storage technology, to supply the energy needs of a wide scale electrical grid was investigated. A number of conclusions can be drawn from the findings:

- It is cost effective to pursue the approach of using battery storage now: Even with no carbon price or cost improvement, the cost was less than using a business as usual fossil fuel approach up to a break even level of $70 \%$ RE. With a price on carbon or cost improvement of the RE technologies, the break even level was pushed higher, and could reach above $99 \%$. However the costs of RE technologies play out in the real world, increasing the level of renewable energy generation on the SWIS from the current low levels using batteries will reduce costs as well as reducing greenhouse emissions for many years to come, even without the benefit of hydroelectricity, pumped hydro storage, bio energy or solar thermal storage.

- Yearly cost improvements in RE technologies can be incorporated into levelised COE estimations. This study developed a simple method to incorporate the continuously improving capital costs of RE technologies over the build duration of the system into the estimation of COE. This approach can be widely adopted, as there is urgency to build these low emission systems now, in order to avoid dangerous climate change, and not wait until some point in the future. It is perhaps more realistic to use this approach rather than estimating projected costs at some point in the future and then calculating the cost of building the entire system based on these costs.

- These findings are applicable to other regions. The finding of this study have positive implications for other regions in the world with variable renewable energy resources and also having to rely on battery storage, or coming to rely on battery storage by default in the absence of policies designed to enable the implementation of other technologies. A cost effective $100 \%$ RE system for these regions seems to be in reach even if there are geographical or policy challenges.

\section{Nomenclature}

$\begin{array}{ll}\text { BAU } & \text { Business as usual } \\ c & \text { Fractional yearly cost improvement } \\ \text { cap } & \text { Plant capacity (MW) }\end{array}$

capcdown Capacity that is off line at any one time (\%) capcost Capital cost (\$million)

$C C \quad$ Capital cost factor ( $\$$ million $/ \mathrm{MW})$

$C C C \quad$ Capital cost factor for new converter equipment (\$million)

CIF Capital cost improvement factor

$C P \quad$ Carbon price $(\$ /$ tonne)

COE Cost of energy (\$/MWh)

cost $_{n} \quad$ Annual cost of power plant $n$

$C R F \quad$ Capital recovery factor

$d \quad$ Discount (investment) rate

EE Energy efficiency

EF Specific emission intensity of fossil fuel generators $\left(\mathrm{kgCO}_{2} \mathrm{e} / \mathrm{MWh}\right)$

EI Emission intensity $\left(\mathrm{kgCO}_{2} \mathrm{e} / \mathrm{MWh}\right)$

ERE Specific emission intensity of renewable energy generators $\left(\mathrm{kgCO}_{2} \mathrm{e} / \mathrm{MW}\right)$

ET Emissions from new transmission lines $\left(\mathrm{kgCO}_{2} \mathrm{e}\right)$

$e_{y} \quad$ Annual energy generated (MWh)

FC $\quad$ Fuel cost (\$million/MWh)

$g \quad$ Fractional installation growth rate

GCC Distributed PV or storage grid connection cost factor $(\$ / \mathrm{kW}$ or $\$ / \mathrm{kWh})$

gridcost Capital cost of new grid infrastructure (\$million)

$i \quad$ Inflation rate $(\%)$

IRF Inflation ratio factor

If Plant lifetime $(\mathrm{y})$

olf Online fraction

$O M C_{f} \quad$ Fixed annual operations and maintenance cost (\$million/MW)

$O M C_{v} \quad$ Variable annual operations and maintenance cost (\$million/MWh)

$\mathrm{P}_{\mathrm{i}} \quad$ One of the parameters used in the calculation of $\mathrm{COE}$

RE Renewable energy (includes energy efficiency measures and storage)

SWIS South west interconnected system

SWWA South west region of Western Australia

$t_{b d} \quad$ System building duration 


$\begin{array}{ll}\text { TCF } & \begin{array}{l}\text { Converter specific emissions intensity } \\ \left(\mathrm{kgCO}_{2} \mathrm{e}\right)\end{array} \\ \text { TLC } & \begin{array}{l}\text { Capital cost factor for new transmission lines } \\ (\$ \mathrm{million} / \mathrm{km})\end{array} \\ \text { tlength } & \begin{array}{l}\text { Length of new transmission line }(\mathrm{km}) \\ \text { Transmission line specific emissions intensity } \\ \text { TLF }\end{array} \\ & \left(\mathrm{kgCO}_{2} \mathrm{e} / \mathrm{km}\right)\end{array}$

Thanks to Murdoch University for supporting my candidature.

\section{References}

1. T.W. Brown, T. Bischof-Niemz, K. Blok, C. Breyer, H. Lund, B.V. Mathiesen, Response to 'Burden of proof: A comprehensive review of the feasibility of $100 \%$ renewable-electricity systems,' Renew. Sustain. Energy Rev. 92, 834-847 (2018)

2. B.V. Mathiesen, H. Lund, K. Karlsson, 100\% Renewable energy systems, climate mitigation and economic growth, Appl. Energy 88, 488-501 (2011)

3. B. Elliston, I. MacGill, M. Diesendorf, Comparing least cost scenarios for $100 \%$ renewable electricity with low emission fossil fuel scenarios in the Australian National Electricity Market, Renew. Energy 66, 196-204 (2014)

4. B. Lu, A. Blakers, M. Stocks, 90-100\% renewable electricity for the South West Interconnected System of Western Australia, Energy 122, 663-674 (2017)

5. A. Sadiqa, A. Gulagi, C. Breyer, Energy transition roadmap towards $100 \%$ renewable energy and role of storage technologies for Pakistan by2050, Energy 147, 518-533 (2018)

6. A. Aghahosseini, D. Bogdanov, L.S.N.S. Barbosa, C. Breyer, Analysing the feasibility of powering the Americas with renewable energy and inter-regional grid interconnections by2030, Renew. Sustain. Energy Rev. 105, 187-205 (2019)

7. M.Z. Jacobson, M.A. Delucchi, Z.A.F. Bauer, S.C. Goodman, W.E. Chapman, M.A. Cameron, C. Bozonnat, L. Chobadi, H.A. Clonts, P. Enevoldsen, J.R. Erwin, S.N. Fobi, O.K. Goldstrom, E.M. Hennessy, J. Liu, J. Lo, C.B. Meyer, S.B. Morris, K.R. Moy, P.L. O'Neill, I. Petkov, S. Redfern, R. Schucker, M.A. Sontag, J. Wang, E. Weiner, A.S. Yachanin, $100 \%$ clean and renewable wind, water, and sunlight allsector energy roadmaps for 139 countries of the world, Joule 1, 108-121 (2017)

8. M.Z. Jacobson, M.A. Delucchi, M.A. Cameron, B.V. Mathiesen, Matching demand with supply at low cost in 139 countries among 20 world regions with $100 \%$ intermittent wind, water, and sunlight (WWS) for all purposes, Renew. Energy 123, 236-248 (2018)

9. W. Zappa, M. Junginger, M. van den Broek, Is a $100 \%$ renewable European power system feasible by 2050? Appl. Energy 233-234, 1027-1050 (2019)

10. D. Connolly, H. Lund, B.V. Mathiesen, Smart Energy Europe: The technical and economic impact of one potential $100 \%$ renewable energy scenario for the European Union, Renew. Sustain. Energy Rev. 60, 1634-1653 (2016)

11. J. Riesz, B. Elliston, P. Vithayasrichareon, I. MacGill, 100\% Renewables in Australia: A Research Summary, Centre for Energy and Environmental Markets, University of NSW, Sydney, 2016
12. B. Rose, S. Gates, S. Begg, L. Bunn, C. Carter, S. Jerejian, A. King, I. Porter, Clean Electricity Western Australia 2030. Modelling Renewable Energy Scenarios for the South West Integrated System, Sustainable Energy Now (SEN), Western Australia, 2016

13. J. Cochran, T. Mai, M. Bazilian, Meta-analysis of high penetration renewable energy scenarios, Renew. Sustain. Energy Rev. 29, 246-253 (2014)

14. W. Deason, Comparison of $100 \%$ renewable energy system scenarios with a focus on flexibility and cost, Renew. Sustain. Energy Rev. 82, 3168-3178 (2018)

15. J.E. Trancik, J. Jean, G. Kavlak, M.M. Klemun, M.R. Edwards, J. McNerney, M. Miotti, P.R. Brown, J.M. Mueller, Z.A. Needell, Technology improvement and emissions reductions as mutually reinforcing efforts: Observations from the global development of solar and wind energy (MIT, 2015)

16. C.L. Benson, C.L. Magee, On improvement rates for renewable energy technologies: Solar PV, wind turbines, capacitors, and batteries, Renew. Energy. 68, 745-751 (2014)

17. Lazard, Lazard's Levelized Cost of Energy AnalysisVersion 11.0, 2017

18. Lazard, Lazard's Levelized Cost of Energy AnalysisVersion 12.0, 2018

19. J.P. Hansen, P.A. Narbel, D.L. Aksnes, Limits to growth in the renewable energy sector, Renew. Sustain. Energy Rev. 70, 769-774 (2017)

20. K. Baldwin, A. Blakers, M. Stocks, Australia's renewable energy industry is delivering rapid and deep emissions cuts, The Energy Change Institute, Australian National University, 2018. http://re100.eng.anu.edu.au/

21. P. Denholm, M. Hand, Grid flexibility and storage required to achieve very high penetration of variable renewable electricity, Energy Policy 39, 1817-1830 (2011)

22. B. Elliston, J. Riesz, I. MacGill, What cost for more renewables? The incremental cost of renewable generation. An Australian National Electricity Market case study, Renew. Energy 95, 127-129 (2016)

23. M. Kemp, J. Wexler, eds., Zero carbon Britain 2030: a new energy strategy: the second report of the zero carbon Britain project (Centre for Alternative Technology, Wales, 2010)

24. H. Lund, B.V. Mathiesen, Energy system analysis of $100 \%$ renewable energy systems - The case of Denmark in years2030 and 2050, Energy 34, 524-531 (2009)

25. D. Connolly, H. Lund, B.V. Mathiesen, M. Leahy, The first step towards a $100 \%$ renewable energy-system for Ireland, Appl. Energy 88, 502-507 (2011)

26. G. Pleßmann, M. Erdmann, M. Hlusiak, C. Breyer, Global Energy Storage Demand for a $100 \%$ Renewable Electricity Supply, Energy Proc. 46, 22-31 (2014)

27. A. Ansar, B. Flyvbjerg, A. Budzier, D. Lunn, Should we build more large dams? The actual costs of hydropower megaproject development, Energy Policy 69, 43-56 (2014)

28. I. Kougias, S. Szabó, Pumped hydroelectric storage utilization assessment: Forerunner of renewable energy integration or Trojan horse?, Energy 140, 318-329 (2017)

29. B. Nykvist, M. Nilsson, Rapidly falling costs of battery packs for electric vehicles, Nat. Clim. Change 5, 329-332 (2015)

30. O. Schmidt, A. Hawkes, A. Gambhir, I. Staffell, The future cost of electrical energy storage based on experience rates, Nat. Energy 2, 17110 (2017) 
31. R. Kempener, E. Borden, Batter* + y Storage for Renewables: Market Status and Technology Outlook, International Renewable Energy Agency (IRENA), 2015

32. AEMO, 2017 Electricity statement of opportunities, Australian Energy Market Operator, Western Australia, 2017. www.aemo.com.au

33. D. Laslett, C. Creagh, P. Jennings, A method for generating synthetic hourly solar radiation data for any location in the south west of Western Australia, in a world wide web page, Renew. Energy 68, 87-102 (2014)

34. D. Laslett, C. Creagh, P. Jennings, A simple hourly wind power simulation for the South-West region of Western Australia using MERRA data, Renew. Energy 96, 1003-1014 (2016)

35. D. Laslett, C. Carter, C. Creagh, P. Jennings, A large-scale renewable electricity supply system by 2030: solar, wind, energy efficiency, storage and inertia for the South West Interconnected System (SWIS) in Western Australia., Renew. Energy (submitted) (2017)

36. A. Burnham, J. Han, C.E. Clark, M. Wang, J.B. Dunn, I. Palou-Rivera, Life-cycle greenhouse gas emissions of shale gas, natural gas, coal, and petroleum, Environ. Sci. Technol. 46, 619-627 (2012)

37. C. Good, T. Kristjansdottír, A. Houlihan Wiberg, L. Georges, A.G. Hestnes, Influence of PV technology and system design on the emission balance of a net zero emission building concept, Sol. Energy 130, 89-100 (2016)

38. I. Kumar, W.E. Tyner, K.C. Sinha, Input-output life cycle environmental assessment of greenhouse gas emissions from utility scale wind energy in the United States, Energy Policy 89, 294-301 (2016)

39. D. Larcher, J.-M. Tarascon, Towards greener and more sustainable batteries for electrical energy storage, Nat. Chem. 7, 19-29 (2014)

40. O. Kelp, G. Dundas, Electricity Sector Emissions. Modelling of the Australian Electricity Generation Sector, ACIL ALLEN CONSULTIN G, Brisbane, 2013

41. A. Nicholls, R. Sharma, T.K. Saha, Financial and environmental analysis of rooftop photovoltaic installations with battery storage in Australia, Appl. Energy 159, 252-264 (2015)

42. I.M. Hoffman, C.A. Goldman, G. Rybka, G. Leventis, L. Schwartz, A.H. Sanstad, S. Schiller, Estimating the cost of saving electricity through U.S. utility customer-funded energy efficiency programs, Energy Policy 104, 1-12 (2017)

43. EPRI, The Australian Power Generation Technology Report, Electric Power Re search Institute, Australia, 2015

44. R. Turconi, C.G. Simonsen, I.P. Byriel, T. Astrup, Life cycle assessment of the Danish electricity distribution network, Int. J. Life Cycle Assess. 19, 100-108 (2014)

45. I.B. Hauan, Life Cycle Assessment of Electricity Transmission and Distribution, Institutt for energi-og prosessteknikk, 2014. https://brage.bibsys.no/xmlui/handle/11250/235701 (accessed March 6, 2017)
46. NREL, NREL: Energy Analysis - Energy Technology Cost and Performance Data, (2013). http://www.nrel.gov/analy sis/tech_lcoe_documentation.html (accessed February 28, 2017)

47. T. Krieg, Transmission Asset Cost Benchmarking. Report summarising SKM benchmarking of selected asset cost estimates to assist in verifying cost models. V0.4, Sinclair Knight Merz, Western Power, Armadale, Western Australia, 2008. www.skmconsulting.com (accessed January 17, 2017)

48. ERA, Draft Determination on the New Facilities Investment Test Application for the Connection of Collgar Windfarm, Economic Regulation Authority, Perth, 2011. www.erawa. com.au (accessed January 17, 2017)

49. CEC, Guide to installing solar PV for business and industry, Clean Energy Council, Melbourne, 2014. cleanenergycouncil. org.au (accessed March 20, 2017)

50. M.Z. Jacobson, M.A. Delucchi, M.A. Cameron, B.A. Frew, Low-cost solution to the grid reliability problem with $100 \%$ penetration of intermittent wind, water, and solar for all purposes, Proc. Natl. Acad. Sci. 112, 15060-15065 (2015)

51. S. Faulstich, B. Hahn, P.J. Tavner, Wind turbine downtime and its importance for offshore deployment, Wind Energy 14, 327-337 (2011)

52. M. Dubarry, A. Devie, K. Stein, M. Tun, M. Matsuura, R. Rocheleau, Battery energy storage system battery durability and reliability under electric utility grid operations: analysis of 3 years of real usage, J. Power Sources 338, 65-73 (2017)

53. J. Cochran, D. Lew, N. Kumarb, Flexible Coal (2013). https://pdfs.semanticscholar.org/8beb/ab4da70a1d0babe1 fee13eccbc6018c9e916.pdf (accessed March 15, 2017)

54. J.P. Gouveia, L. Dias, I. Martins, J. Seixas, Effects of renewables penetration on the security of Portuguese electricity supply, Appl. Energy. 123, 438-447 (2014)

55. A. Blakers, B. Lu, M. Stocks, $100 \%$ renewable electricity in Australia, (2017). http://energy.anu.edu.au/files/100\%25\% 20renewable\%20electricity\%20in\%20Australia.pdf (accessed March 15, 2017)

56. K. Field, UBS Analyst Dubs Model 3 Unprofitable, Tesla Responds With Battery Pricing, CleanTechnica (2016). https://cleantechnica.com/2016/04/27/tesla-model-3-pric ing-battery-pricing-unveiled/ (accessed March 18, 2017)

57. Jacobs, NSW Energy efficiency programs Cost benefit analysis, Jacobs Group (Australia) Pty Limited, Melbourne, 2014

58. T.S. Brinsmead, P. Graham, J. Hayward, E.L. Ratnam, L. Reedman, Future energy storage trends: an assessment of the economic viability, potential uptake and impacts of electrical energy storage on the NEM 2015-2035, CSIRO, Australia, 2015

59. J. Lu, S. Hyland, Energy Price Limits for the Wholesale Electricity Market in Western Australia. Final draft report 1.4, Jacobs, Melbourne, 2016

60. B.S. Howard, N.E. Hamilton, M. Diesendorf, T. Wiedmann, Modeling the carbon budget of the Australian electricity sector's transition to renewable energy, Renew. Energy 125, $712-728(2018)$

Cite this article as: Dean Laslett, Can high levels of renewable energy be cost effective using battery storage? Cost of renewable energy scenarios for an isolated electric grid in Western Australia, Renew. Energy Environ. Sustain. 5, 6 (2020) 